\title{
Corporate Failure: A Non Parametric Method
}

\author{
Ben Jabeur Sami ${ }^{\mathrm{a}}$ \\ ${ }^{a}$ IESEG School of Management, , France
}

\begin{abstract}
A number of authors suggested that the impact of the macroeconomic factors on the incidence of the financial distress, and afterward in case of failure of companies. However, macroeconomic factors rarely, if ever, appear as variables in predictive models that seek to identify distress and failure; modellers generally suggest that the impact of macroeconomic factors has already been taken into account by financial ratio variables. This article presents a systematic study of this domain, by examining the link between the failure of companies and macroeconomic factors for the French companies to identify the most important variables and to estimate their utility in a predictive context. The results of the study suggest that several macroeconomic variables are strictly associated to the failure, and have a predictive value by specifying the relation between the financial distress and the failure.
\end{abstract}

Keywords: Financial Distress; Macroeconomic Variable; Partial Least Squares (Pls)

\section{(C) 2013 Published by SSBFNET}

\section{Introduction}

Since the crisis of the 1930, the early work of writers such as Fitzpatrick (1932) and the financial crisis of 2008, the problem of failure has become a field of investigation of research in its own right. According to Franks and Sussman (2005), a firm is defined as being in distress once the local branch or regional credit manager decides to transfer a status report to the monitoring unit of economic enterprises or responsible financial diagnosis. Such decisions may occur, especially for SMEs, in the case of violations of certain terms (non-payment of interest exceeding the overdraft limit ...), or following a poor assessment of the future of the firm by directors of credit (by reference to indicators such as high debt and low profitability). The interest of this research is to identify macroeconomic determinants of failure of SMEs, and to provide a better model to anticipate financial distress, to overcome the deficiency associated with traditional methods. The above arguments yield the following hypothesis for testing: "There is significant relationship between macroeconomic variables and financial distress".

This article suggests analyzing the role of the macroeconomic variables in the financial distress of the French companies.

\section{Literature review}

At the macroeconomic level, economists are very fast link failure, cycle and crisis. In the thirties, the Keynesian theory laid the foundations of modern analysis with emphasis on the role of consumption, the capitalization of the money supply, the interest rate and the gap between production and demand. Previous studies show clearly that the macroeconomic aggregates can be used to explain the failure of companies. Altman (1983, 2006) assumes that macroeconomic conditions may intervene in any significant way in the phenomenon of failure. It will examine first, the influence of economic factors on business bankruptcy and then it models this phenomenon.

To do this, on the basis of past and recent work, we believe that macro environmental factors may trigger the failure, are closely related to economic conditions, the number of start-ups, the money market, the credit policy at the foreign

\footnotetext{
${ }^{a}$ Corresponding author. Ben Jabeur Sami, Tel.: +336 11098584.
} 
exchange market, the change in the price level and opening the economy to foreign trade. The survival of the company depends, in part, on economic conditions. A difficult situation can lead to poor structure of sales, a level of sales prices inconsistent with the market and therefore, insufficient profitability (Liou and Smith, 2007). The interest for a better understanding of the mechanisms of failure is often accentuated in times of economic recession (Lev, 1974; Delion, 2008; Blot and Le Bayon, 2009; Mare, 2012). Mensh (1984) shows that the increase in failure during an economic recession is linked to factors external to the company. Altman (1984) and Johnson (1974) argue that the failure rate increases during recessions and decreases during periods of expansion, and it is possible to retain the GNP (gross national product) and profits of all firms as indicators of economic growth and general health of the economy. Why they establish a systematic correlation between bankruptcy and economic crisis. In the same context, Sung et al (1999) examined the characteristics of the periods of recession and expansion and the ability to use them for an explanation of business failures.

Several research studies have tried to highlight the macroeconomic variables on corporate bankruptcy based on econometric regression models that take into account the phenomenon of delay (Khoufi and Feki, 2004; Rose and al 1982; Altman, 1983). In the light of this method, a new model was considered by Rose and al (1982) to consider the possibilities of delay, ranging from one to four quarters. The risk of loss varies with the age of the company. In this regard, Pompe and Belderbeek (2005), became interested in the prediction of failure based on a sample of Belgian SMEs between 1986 and 1994 by making a distinction between companies with more than eight years and those less than eight years. By analogy with the work of Pompe and Belderbeek (2005), Thornhill and Amit (2003) examine the determinants of the failure of young and old businesses on a sample of 339 Canadian firms in 1996. These authors conclude that young businesses fail due to a lack of experience in general management and gaps in financial management skills. However, the failure of the oldest companies is more the inability to adapt to the changing environment.

Using data from the U.S. Census industry between 1963 and 1982, Dunne et al (1989) lead to the conclusion that the activities that have the highest entry rates are also those with the strongest rate of output. More recently, Jayet (1993), after analyzing the sectoral and spatial distributions of rates of creation and destruction between 1988 and 1992 , concluded that these rates are substantially equivalent. Credit conditions and money market appear to be the main causes of business failure. Several studies have been performed including the average interest rate of bank loans, money supply (M2) and using different statistical and econometric techniques (Khoufi and Feki, 2004). Indeed, the evolution of the money supply indicates the level of corporate liquidity, while the increase in the interest rate of bank loans due to a difficult business. Empirically detect factors explaining the policy of granting loans to investment firms raised for years already, the interest of several researchers (Turner and al, 1992; Helal, 1994, Smith 2002, 2007). Malecot (1981) states that the relationship between economic market conditions and the failure of an operation is usually based on a tightening of banking terms, a credit crunch or a higher interest rate. Isachenkova Hunter (2004), Bhattacharjee and al $(2002,2004)$, and have found a negative impact of the depreciation of the dollar on the lives of British companies. This result explains the drop in the exchange rate in a disadvantage on local production. Generally, the exchange rate has opposite effects on the rate of business failure effects. Indeed, the increase in the exchange rate has a positive impact on the profitability of exporting firms. Economic instability associated with high inflation and unanticipated movements in interest rates have an effect on the rate of liquidation of companies depends on the composition of their debt. More companies are leveraged, the risk of failure is high, unlike companies financed by fixed-rate debt, which they may be vulnerable to an unexpected reduction in the interest rate (Isachenkova and Hunter, 2004). In this regard, they point out that the increase in interest rates generates multiple effects, including a decline in bond prices and an increase in interest on the debt, which is one of the adverse effects of inflation on business. Thus, Wadhwani (1986) states that: in the short term the company must adapt to the increase in the nominal interest rate to lower its debt, while in the long term it should lower the costs of these inputs. Following an increase in the nominal interest rate and inflation, he adds that companies financed by variable rate debt would be unable to increase their debt and unable to meet their commitments short term.

\section{Financial distress}

Logic suggests that the major factor affecting company failure rate would be the overall economic circumstances within which companies are operating. On the macroeconomic level, there are a link between bankruptcy and crisis cycle. 
Previous studies have showed clearly that macroeconomic aggregates can be used to explain business failure. Altman (2006) assumes that macroeconomic conditions may intervene in any important way, in the phenomenon of failure. Altman (1983) argues that the failure rate increases during recessions and decreases during periods of expansion. In the same context, Sung and al (1999) examined the characteristics of these periods (recession and expansion) and the possibility of their use for the explanation of corporate failures recorded on the basis of a sample of firm Korean industrial. EL Hennawy and Morris (1983) had deduced that all companies are vulnerable to a greater or lesser degree at different stages in economic cycles and that companies operating in different industries are more at risk at particular points.

Bunn and Redwood (2003) use probabilistic models in which they introduce the monthly growth rate of industrial production as an indicator of economic conditions. They found that the company is bound to fail during periods of recession in the economic cycle. Altman (2006) argues that when the number of start-ups increases, bankruptcies are increasing too. Koeing (1985) showed that $50 \%$ of bankruptcies are the result of business with fewer than five years of age. Dunne and al (1989) lead to the conclusion that activities with the entry rate highest are also those rates out stronger. Agrawal and Taffler (2003) and Bunn( 2003), Koopman and Lucas (2003) have demonstrated a strong during co-cyclicality between credit and default cycles and Gross Domestic product(GPD) at frequencies of six years and a significant co-cyclicality between GPD and business failure over a frequency of eleven years. Malecot (1981) shows that the relationship between economic conditions and the business market failure is usually based on a tightening of banking, the credit crunch or rising interest rates.

Altman (1983) finds that firms rarely marginal state, their failure as the loans are available to him. The measures have been chosen to reflect the conditions of credit and liquidity in the money supply, reserves and interest rates. Therefore, increasing the interest rate is rarely tolerated by businesses, especially the most vulnerable. Sharabany (2004) argues that the evolution of exchange rates and credit policy has an effect on business failure. In France, Malécot (1991) believes that the bankruptcy resulted from a series of competitive forces that compel the company to adopt a standard production compatible with them. And therefore the problem of bankruptcy is related to the concept of marginal enterprise: Enterprises that are unable to sell enough to cover their costs are bound to make losses, and then disappear.

In the next section, we describe the new approch of regression, the database used in the study and the choise of macroeconomic variables.

\section{Methodology}

The assessment of the causes of failure is necessary to develop and use models to anticipate and prevent, and can be very useful for banks when granting loans, but also for all other investors. Thus, these models predict business failure is primarily a "warning system" and then a decision tool. It is for these reasons that we wanted to present the evaluation of the risk of business failure by a parametric approach as the primary focus of this research, while the second line will be dedicated to the non-parametric approach made by the PLS (Partial least squares).

\subsection{PLS regression}

PLS united diverse regression is a nonlinear model between a single dependent variable $\mathrm{Y}$ to a set of independent variables quantitative or qualitative $X_{1} \ldots X_{k}$ (Wold 1983). It can be achieved by following simple and multiple regressions. By exploiting the statistical tests associated with linear regression, it is possible to select the significant explanatory variables to keep in the PLS regression and to choose the number of PLS components to retain.

There are several versions of the algorithm of univariate regression PLS1. They differ at the level of the normalizations (standardizations) and the intermediate calculations, but they give quite the same regression. According to Bastien, Esposito and Tenenhaus (2005). The algorithm can be decomposed as follows:

We construct first a component PLS $t_{1}$ :

with: $t_{1}=w_{11} X_{1}+\ldots+w_{1 k} X_{k}$

where: 


$$
w_{1 j}=\frac{\operatorname{cov}\left(Y, X_{j}\right)}{\sqrt{\sum_{j=1}^{k} \operatorname{cov}\left(Y, X_{j}\right)^{2}}}
$$

These coefficients are then normalized:

$$
w_{1 j}^{*}=\frac{w_{1 j}}{\sqrt{\sum_{j=1}^{k}\left(w_{1 j}\right)^{2}}}
$$

Then we perform a simple regression of $\mathrm{Y}$ on $t_{1}$ :

$$
\hat{Y}=c_{1} t_{1}+Y_{1}
$$

where are the regression coefficient and the vector Y1 residue. Hence a first regression equation:

$$
\hat{Y}=c_{1} w_{11} X_{1}+\ldots+c_{1} w_{1 k} X_{k}+Y_{1}
$$

whose coefficients are easily interpretable.

However if one considers that the explanatory power of this model is low, it seeks a second component, a linear combination of $\mathrm{Xj}$, unlinked and explaining to the residue $\mathrm{Y} 1$.

This component is a linear combination of residuals of regression variables $\mathrm{Xj}$ on the component:

With: $x_{1 j}=X_{j}-p_{1 j} t_{1}$

and $p_{1 j}=\frac{\operatorname{cov}\left(X_{j}, t_{1}\right)}{\operatorname{var}\left(t_{1}\right)}$

Then obtained $t_{2}$ :

$t_{2}=w_{21} x_{11}+\ldots+w_{2 k} x_{1 k}$

where:

$$
w_{2 j}=\frac{\operatorname{cov}\left(x_{1 j}, Y_{1}\right)}{\sqrt{\sum_{j=1}^{k} \operatorname{cov}^{2}\left(x_{1 j}, Y_{1}\right)}}
$$


This is followed by a multiple regression of $\mathrm{Y}$ on $t_{1}, t_{2}$ :

$\hat{Y}=c_{1} t_{1}+c_{2} t_{2}+Y_{2}$

Where $c_{1}$ and $c_{2}$ are the regression coefficients Y2 and the vector of residuals.

$\hat{Y}$ Written as a function of variables by replacing components $\mathrm{t} 1$ and $\mathrm{t} 2$ by their values based on $\mathrm{X}_{\mathrm{j}}$ :

$\hat{Y}=c_{1} \sum_{j=1}^{k} w_{1 j} X_{j}+c_{2} \sum_{j=1}^{k} w_{2 j}\left(X_{j}-p_{1 j} \sum_{j=1}^{k} w_{1 j} X_{j}\right)$

We can iterate this process using the same manner the residues $Y_{2}, X_{21}, \ldots, X_{2 k}$ regressions of $Y, X_{1}, \ldots, X_{k}$ on $t_{1}, t_{2}$.

The number of components to retain is usually determined by a cross validation.

For each value h, we compute predictions of the variable interest $\mathrm{Y}$. Specifically we calculate the prediction $\hat{Y}_{h i}$ of $\mathrm{Y}_{\mathrm{i}}$

using all individuals and $\hat{Y}_{h(-i)}$ without using individual "i”. Then we calculate the criteria $R S S_{h}$ (Residual Sum of

Squares) and $\mathrm{PRESS}_{h}$ (Prediction Error Sum of Squares) defined by:

$R S S_{h}=\sum_{i=1}^{n}\left(Y_{i}-\hat{Y}_{h i}\right)^{2}$

and $\operatorname{PRESS}_{h}=\sum_{i=1}^{n}\left(Y_{i}-\hat{Y}_{h(-i)}\right)^{2}$

According Umetri (1996) the component $t_{h}$ will be withheld if:

$$
\sqrt{P R E S S_{h}} \leq 0.95 \leq \sqrt{R S S_{h-1}}
$$

\subsection{Data}

We try to explain the monthly number of failures of the French companies (NF) by a set of the explanatory variables stemming from the financial literature. For this, the theoretical choice of variables will be based on the work of Altman (1984), Graves and Smith (2002), Liou and Smith (2007).

The variables chosen for our analysis are summarized as follows: The number of creation of the new companies (NCE), consumer prices index (IPC), industrial product price index (IPI), money supply (M2), producer price index (PPI). The research results are based on data from the Frensh National Institute of Statistics (INSEE) over the period 1999-2008. 


\subsection{Results of Univariate and multivariate regression}

The results of univariate regression are presented in the following table:

Table 1. Results of univariate regression

\begin{tabular}{llll}
\hline Explanatory variables & Coefficient & Statistic t & Probability \\
\hline NCE & 0.947 & 0.158 & 0.000 \\
IPI & 0.952 & 34.576 & 0.000 \\
IPC & 0.956 & 36.339 & 0.000 \\
M2 & 0.881 & 416.104 & 0.000 \\
PPI & 0.958 & 33.532 & 0.000 \\
\hline
\end{tabular}

This table shows that all variables are significant with 5\% risk with a high regression coefficient for $\mathrm{M} 2$ variable.

To explain the evolution of the number of bankruptcy (NF), we introduce all variables in the analysis:

$$
\mathrm{NF}=\beta_{1} N C E+\beta_{2} I P I+\beta_{3} I P C+\beta_{4} M 2+\beta_{5} P P I+\varepsilon
$$

The results found are summarized in the following table:

Table 2. Results of multivariate regression

\begin{tabular}{llll}
\hline Explanatory variables & Coefficient & Statistic t & Probability \\
\hline NCE & 0.055 & 2.762 & 0.007 \\
IPI & 1.007 & 0.144 & 0.886 \\
IPC & 15.813 & 0.557 & 0.578 \\
M2 & -31.150 & -0.932 & 0.353 \\
PPI & 6.842 & 0.232 & 0.817 \\
\hline
\end{tabular}

In the multivariate model, only the consumer prices index is significant with $5 \%$ risk. The Adjusted $\mathrm{R}$ Square is around $95.7 \%$, hence our explanatory variables are adequate to explain the number of bankruptcy. Other variables are declared not significant at the risk of $5 \%$, in spite of are him when they are separately taken, this problem is due to the strong correlation between all variables, and the same signs of regression coefficients are inconsistent with the work of Altman (1984). Hence the interest of the PLS1 regression that links the variable to explain to all variables.

\subsection{Results of PLS regression}

Having identified one component by cross validation, our new regression equation is:

$$
\mathrm{NF}=0,124 N C E+0,044 I P I+0,093 I P C+0,066 M 2+0,0874 P P I
$$

The regression coefficient of variable creation of new enterprises is positive, that mean's that more new Companies, more there are bankruptcies. The results found confirm the work of Altman (1983) even if we did not use the same transformations or the same number of observations than the latter. We can confirm this result we appeal to the 
method of Wold (1983), which uses the VIP (Variable Importance for Projection variable) to measure the contribution of every variable to the process of the failure, with a minimum important threshold equal to 0.8 .

Table 3. Variable importance in projection

\begin{tabular}{ll}
\hline Explanatory variables & VIP \\
\hline CNE & 1.4259 \\
IPC & 1.0671 \\
PPI & 0.9979 \\
M2 & 0.7541 \\
IPI & 0.5132 \\
\hline
\end{tabular}

We can conclude that the number of creation of the new companies to the largest impact on business failure, say the work of Altman $(1984,2006)$ that established a systematic correlation between bankruptcy and economic crisis. Similarly the variable IPC ranks second in the process of financial distress. The index of producer prices (PPI) occurs at the third position as an indicator of economic growth and general health of the economy, joining studies of Tirapat and Nittayagasetwat (1999), Bunn and Redwood (2003). These authors use probabilistic models in which they introduce the monthly growth rate of industrial production as an indicator of economic conditions. They found that the company is closely linked to the failure during periods of recession in the economic cycle: the current financial crisis, as noted Malecot (1991).

\section{Conclusion}

The results of our study show that there is a real impact of macroeconomic variables on the deteriorating financial situation of French companies. In the term of this work, the phenomenon of failure of companies can be explained by several macroeconomic factors. However, these factors must be handled with caution, because the effects of the macroeconomic factors do not show themselves on all the companies. Indeed, when the situation is favorable, we always find in the same business sector of the companies which remain successful and the others who declare their cessation of payments, in this domain, there is no fate.

The failure should so be, rather, considered the resultant of outside data and the behavior of the firm. These macroeconomic factors are not thus, often decisive in the phenomenon of failure of companies. They must be considered, rather, as catalysts. They are not only enough, to make the company precipitate towards the ruin when she is managed well. Everything depends, internal and specific factors to every company.

Finally, we believe that these results can be improved by increasing the sample size, considering such data over a long period or integrating other macroeconomic variables.

\section{References}

Altman, E.I. (1968). Financial ratios, discriminant analysis and the prediction of corporate bankruptcy. Journal of Finance, 23(4), September, 589-609.

Altman, E.I. (1984). The success of business failure prediction models: an international survey. Journal of Banking and Finance, 8(2), 171-198.

Altman, E.I., Marco, G., \& Varetto, F. (1994). Corporate distress diagnosis: comparisons using linear discriminant and neural networks: the Italian Experience. Journal of Banking and Finance, 18, 505-529.

Altman, E., \& Hotchkiss, E. (2006). Corporate financial distress and bankruptcy: predict and avoid bankruptcy, 3rd Edition, John Wiley \& Sons.

Albert, A., \& Anderson, J. (1984). On the Existence of Maximum Likelihood Estimates in Logistic Regression Models. Biometrika, 71(1), 1-10.

Avishur, A., \& Tsoref, Y. (2001). On the Predictability of Kibbutz Financial Distress: A Principal Component Analysis with Bootstrap Confidence Intervais. Journal of Accounting Auditing \& Finance, winter, 16(1), 55-91.

Baldwin, C., \& Scott, M. (1983). The resolution of claims in financial distress: the case of Massey Ferguson. Journal of Finance, 38, 505-16. 
Bardos, M. (1998). Detecting the risk of company failure at the Banque of France. Journal of Banking and Finance, 22, 1405-1419.

Bastien, P., Esposito, V., \& Tenenhaus, M (2005). PLS generalised linear regression. Comput. Stat. Data Anal,.48(1), 17-46.

Blot C., Le Bayon S., Lemoine M., \& Levasseur S. (2009), De la crise financière à la crise économique : Une analyse comparative France-États-Unis, Revue de L'OFCE, 110, 256-281.

Pompe P.M., \& Bilderbeek J. (2005), The prediction of bankruptcy of small and medium sized industrial firms, Journal of Business Venturing, 20,847-868.

Bhattacharjee A., Higson C., Holly S., \& Kattuman P. (2002), Macro economic instability and business exit: determinants of failures and acquisitions of large UK firms, Accounting subject AREA, Working paper, 02-034, London Business School.

Bhattacharjee A, Higson C, Holly S., \& Kattuman P. (2004), Business failure in UK and US quoted firms: impact of macroeconomic instability and the role of legal institutions, Cambridge Working paper in Economics $\mathrm{N}^{\circ} 0420$, March 2004.

Derquenne, C., \& Hallais, C. (2004). Une méthode alternative à l'approche PLS : Comparaison et Application aux modèles conceptuels marketing. Revue de statistique Appliquée, LII (3), 85-100.

Fort, G., \& Lambert-Lacroix, S. (2005). Classification using Partial Least Squares with Penalized Logistic Regression. Bioinformatics, 21(7), 1104-1111.

Franks, R., \& Sussman, O. (2005). Financial Distress and Bank Restructuring of Small to Medium. Size UK Companies. Review of Finance, 9, 65-96.

Guilhot, B. (2000). Défaillances d'entreprise : soixante-dix ans d'analyse théoriques et empiriques. Revue Française de Gestion, 130, 52-67.

Laitinen, E. (1991). Financial ratios and different failure processes. Journal of Business Finance and Accounting, 18(5), 649-673.

Laitinen, E.K., (1992). Prediction of failure of a study of newly founded firm. Journal of Business Venturing, 7, 323340 .

Liou, D., \& Smith, M. (2007). Macroeconomic Variables and Financial Distress. Journal of Accounting-Business and Management, 14, 17-31.

Malécot, J.F. (1991). Analyse historique des défaillances d'entreprises: une revue de la littérature. Revue d'économie financière, 19, 205-226.

Mare, D. S. (2012). Contribution of macroeconomic factors to the prediction of small bank failures. Paper presented at 4th International IFABS Conference, Valencia, Spain

Nguyen, D., \& Rocke, D. (2004). On partial least squares dimension reduction for microarraybased classification: a simulation study», Comput. Stat. Data Anal, 46, 407-425.

Opler, T. \& Titman, S. (1994). Financial Distress and Corporate Performance. Journal of Finance, 49, 3,1015 - 1040.

Ohlson, J.A. (1980). Financial ratios and the probabilistic prediction of bankruptcy. Journal of Accounting Research, spring, 109-131.

Sung, T.K., Chang, N., \& Lee, G. (1999). Dynamics of modeling in data mining: interpretive approach to bankruptcy prediction. Journal of Management Information System, 16(1), 63-85.

Tenenhaus, M. (1998), La régression PLS : théorie et pratique, Technip, Paris.

Tenenhaus, M. (1999), «L’approche PLS», Revue de Statistique Appliquée, 47(2), 5-40.

Wruck, K. (1990). Financial Distress, Reorganization, and Organizational Efficiency. Journal of Financial Economics, 27, pp. 419-444. 